\title{
A Matemática no Universo da Música
}

\author{
Mathematics in the music universe
}

Rosa García Márquez, Universidade Federal do Rio do Janeiro, rosagmarquez@yahoo.com.br Andréa Zander Vaiano, andreazanderv@yahoo.com.br Rosana de Oliveira, rosanamusica@oi.com.br

\begin{abstract}
Resumo: A Música é a arte mais popular do conhecimento humano. Desde 2011, tornou-se parte obrigatória da grade curricular do Ensino Básico das escolas públicas e privadas do Brasil. Porém, deixou-se a critério de cada instituição decidir o conteúdo a ser desenvolvido. Professores das séries iniciais optam por não trabalhar a Música por se sentirem inseguros. Por outro lado, quando a utilizam como recurso pedagógico, valorizam mais seus aspectos extramusicais. Nesse contexto, foi desenvolvido este trabalho no qual se pretende descrever as relações existentes entre a Matemática e a Música, enriquecer o conhecimento do professor, bem como apresentar maneiras de abordar a Música por meio dos conteúdos de Matemática.
\end{abstract}

Palavras-chave: Música; Matemática; Ensino Básico; Multidisciplinaridade.

\begin{abstract}
Music is the most popular art of the human knowledge. Since 2011, it became an obligatory part to the curriculum of Basic Education of public and private schools in Brazil. However, each school can resolve the content that will be developed. Teachers of the early grades choose not to work Music content because they feel insecure. On the other hand, when they choose to use Music as a teaching resource, they valorize its extra musical aspects more. In this context, this work was developed intending to describe the relationships between Mathematics and Music, enrich the teacher's knowledge, as well as provide ways to approach Music through the Mathematics contents.
\end{abstract}

Keywords: Music; Mathematics; Basic Education; Multidisciplinary.

$\mathrm{N}^{a}$ a década de 1970, a Música era uma disciplina obrigatória do currículo escolar e objetivava desenvolver a criatividade da criança. Porém, era feito de forma despreparada, indiscriminada e desvinculada de um projeto coletivo pela maioria dos professores, perdendo o sentido. 0 projeto de lei n 11.769, que incluiu a Música nas aulas de Educação Artística, foi proposto pela atual governadora do Maranhão, Roseana Sarney, e sancionado pelo ex-presidente Lula em agosto de 2008. A lei, que deveria entrar em vigor nas instituições escolares, públicas e particulares até final de 2011, teve a sua inclusão obrigatória no Ensino Básico prorrogada para 2012.

Da creche ao quinto ano deve ser implementada uma iniciação musical que objetiva aumentar a criatividade (Figueiredo, 2007), desenvolver as habilidades motoras, a capacidade de concentração e a memorização do aluno, bem como a capacidade de interação em grupo, o que ajudará no processo de alfabetização e no raciocínio lógico em Matemática (BRASIL, 2006).

O currículo do ensino da Música não tem ementa definida, ficando, desse modo, a critério de cada escola a elaboração do programa a ser desenvolvido. Entretanto, pressupondo que nem todas as escolas têm infraestrutura adequada para a realização do trabalho, cabe ao docente adaptar-se às diferentes situações, usando a sua criatividade.

Como ainda há carência de professores capacitados para essa tarefa, o MEC (BRASIL, 2006) oferece cursos de formação para incentivar e habilitar esses profissionais.

\section{A Música na EducaÇão}

Ações que podem ser observadas, combinando a música com o ensino de disciplinas, estão relacionadas a seguir.

\section{Projeto MPB nas Escolas}

Antecipando-se à lei no 11.769, o Instituto Cultural Cravo Alvim, em parceria com a Secretaria Estadual de Educação (SEEDUC), elaborou o projeto MPB nas Escolas, que objetiva apresentar ao aluno a origem da música popular, a 
influência dos compositores na formação cultural do país e o contexto das canções de maneira interdisciplinar, através de DVDs, cartazes, livros e um CD, explicando como se deu a formação da MPB.

\section{Projeto Drummath}

Em 1999, Carlos Eduardo Mathias, professor do Instituto Benjamin Constant, situado na Urca, Rio de Janeiro, elaborou uma metodologia para o ensino de Matemática nas séries iniciais de crianças que têm deficiência visual. Por meio de atividades rítmicas, o aluno aprende números pares e ímpares, números primos e múltiplos.

A ideia do professor Mathias foi fundamentada na teoria do médico e psicólogo francês Henri Wallon (1879-1962) (MOTTA, 1999), que se baseava na ligação entre os aspectos cognitivos, motores e afetivos de um indivíduo.

\section{Ligações entre a Música e a Matemática}

A Matemática esteve presente em toda a história da Música, seja na fundamentação teórica ou na composição musical. Provavelmente, uma das primeiras tentativas de organizar e compreender o espectro sonoro no ocidente foi na Grécia antiga, há mais de 500 anos a.C. O matemático grego Pitágoras (570 a.C - 497 a.C.) foi o protagonista dos estudos matemáticos-musicais, ao perceber que o som de uma corda esticada produzia sons graves e agudos, segundo sua divisão.

Na acústica se estudam as vibrações, oscilações, tipos de onda que são produzidos por um som. A forma de onda pode ser descrita matematicamente pela função seno ou senoide, em termos de sua amplitude, frequência e comprimento de onda. Na afinação dos instrumentos é por vezes necessário usar as proporções entre as frequências e definir ajustes, chamados temperamentos.

Na teoria, a divisão da Música em compassos, a representação em forma de frações (Schaefer et al. 1991), o número de valores (figuras de som) a serem utilizados para preencher os tempos dos compassos (Morais, 1983), são praticamente, na sua totalidade, explicados por meio da Matemática.

Na composição musical erudita, usam-se, há muito tempo, propriedades de alguns números ou proporções especiais e transformações geométricas. Alguns compositores modernos recorrem a teorias matemáticas mais complexas, como, por exemplo, a dos processos estocásticos.

\section{Atividades Propostas}

O mundo vive numa profusão de ritmos, vivenciados sob diversos aspectos: no relógio, no andar das pessoas, no voo dos pássaros, nos pingos de chuva, nas batidas do coração, num motor, numa banda, num piscar de olhos, nas brincadeiras e nos trabalhos manuais. Mesmo as crianças de pouca idade que mal conseguem falar já acompanham, a seu modo, uma música, seja tentando balbuciar palavras, batendo palmas ou dançando. Por isso, há uma necessidade de desenvolver nas crianças pequenas o senso de ritmo (Ferreira et al., 2010). Se o saber é construído a partir da interação da criança com o ambiente, e o ritmo é parte primordial do mundo que a cerca, cabe a nós, educadores, levá-la a descobrir, observar, analisar e compreender os ritmos do mundo através da música, do canto, do contato com instrumentos musicais, da dança e do teatro.

São encontrados alguns exemplos de brincadeiras e cantigas em composições, no universo do cancioneiro popular infantil, que estimulam a percepção de ritmo e som e podem ser usadas em sala de aula pelo professor. Como, por exemplo, brincadeiras de pular corda, bater com a bola no chão, entre outras.

Nesta seção apresentamos alguns métodos e atividades que podem ser realizadas em sala de aula na relação entre Música e Matemática (Simonato, 2005).

- Realizar experimentos de ritmo e som, introduzindo conceitos musicais básicos e as notas musicais.

- Brincar com as músicas do cancioneiro infantil, com o intuito de testar a concentração dos participantes.

- Usar o compasso simples no ensino da contagem e da escrita dos primeiros numerais.

- Extrair conteúdos matemáticos, implícitos ou explícitos, de diferentes canções.

- Construir sequências músico-corporais.

\section{Ritmo e Som: Atividades Práticas}

Serão apresentadas atividades práticas, de caráter coletivo, que podem ser desenvolvidas em sala de aula com as devidas adaptações. 


\section{Atividade 1: Propriedades do Som (altura) \\ Público-Alvo - Educação Infantil}

Objetivos - Diferenciar som grave de agudo; estimular a memorização.

\section{Desenvolvimento}

Cantar a música (Fig. 1) realizando o que ela propõe, ou seja, o bater de palmas e pés.

O choque entre as mãos abertas produzirá um som mais agudo que a batida dos pés, que, consequentemente, produzirá um som mais grave que as palmas.

\section{Atividade 2: 0 Barquinho}

Público-Alvo - Educação Infantil (5 - 6 anos)

Objetivos - Vivenciar o pulso e a divisão do compasso binário, o ritmo, a concentração; trabalhar com as figuras geométricas, quantidade e conjuntos.

\section{Desenvolvimento}

1. Cantar com as crianças a música "O Barquinho"(Fig. 2).

2. Dividir a turma em duplas. Os pares sentados no chão de pernas cruzadas de frente um para o outro darão as mãos e realizarão o movimento rítmico de ir e vir, enquanto cantam a música.

\section{Caranguejo \\ (Folclore Brasileiro)}

Palma, palma, palma (bate palmas)

Pé, pé, pé (bate o pé no chão)

Roda, roda, roda (roda em torno de si)

Caranguejo, peixe é (no "é" se agacha)

Figura 1: Letra da música "Caranguejo"
3. Cada aluno deve confeccionar seu barquinho de papel.

4. Desenhar no chão (com giz ou fita crepe) quatro figuras geométricas planas que esteja trabalhando com os alunos. Designe uma figura para cada conjunto dos integrantes da turma. Exemplo: triângulo para os meninos, quadrado para as meninas e círculo para o professor.

5. Reforçar com o grupo as figuras desenhadas, solicitando que todos os meninos deixem seus barquinhos dentro do triângulo, as meninas no quadrado e o professor no círculo.

6. Trabalhar a quantidade de elementos em cada conjunto; conjunto unitário (professor); escrita do numeral que representa a quantidade do conjunto dos meninos e das meninas.

\section{O Barquinho}

(autor: Zélia B. Moraes)

Está chovendo

Vou colocar meu barquinho de papel

Pra enxurrada levar (BIS)

Não sei pra onde vai

Nem como vai parar

Talvez pare ali

Talvez chegue ao mar

Talvez pare ali

Talvez chegue ao mar!

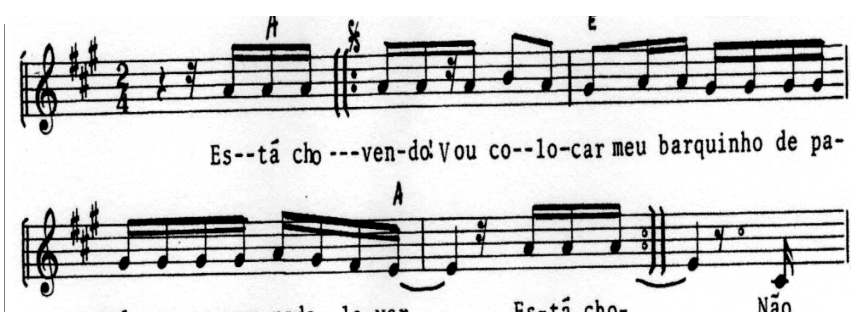

pel pra en-xur-rada le-var.

Es-tá cho-

A

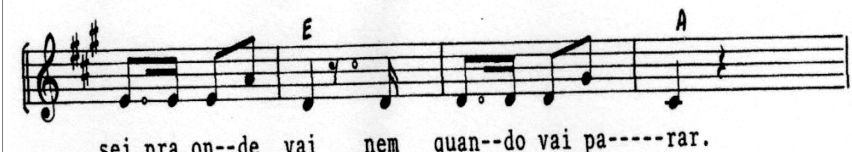

sei pra on--de vai, nem quan--do vai pa--.--rar.

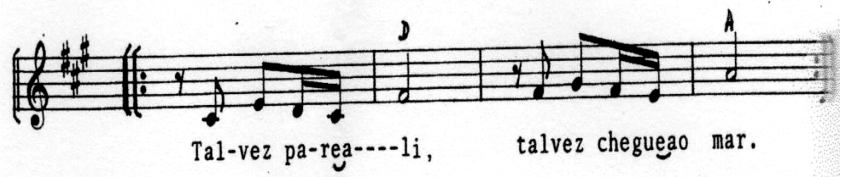

Figura 2: Letra e partitura da música "O Barquinho" 


\section{Atividade 3: Trabalhando a concentração}

Público-Alvo - Turmas a partir do 6o ano do Ensino Fundamental - 11 anos em diante. (Não há limite máximo de idade).

Objetivos - Trabalhar o ritmo e a concentração.

\section{Desenvolvimento}

Praticar o canto coletivo com a música Sambalelê (Fig. 3).

Andar pela sala cantando a música e percebendo a divisão binária (1- 2; 1- 2)
Praticar a fala ritmada do contracanto:

samba, sambalelê, pisa, barra da saia;

samba, sambalelê, pisa, barra da saia!

Dividir a turma em dois grupos. Designar um grupo para o contracanto.

No refrão: "(...) samba, samba, sambalelê(...)" o grupo 2 entra com a fala ritmada sob a mesma letra. Ambos se encontrarão ao final. Ressaltar a concentração para que os grupos não se percam.

Inverter os grupos para que ambos experimentem o contracanto.

\section{Sambalelê}

(Folclore Brasileiro)

Sambalelê tá doente

Tá com a cabeça quebrada

Sambalelê precisava

é de umas oito lambadas.

Pisa, pisa, pisa, mulata

Pisa na barra da saia, mulata!

Pisa, pisa, pisa, mulata

Pisa na barra da saia.
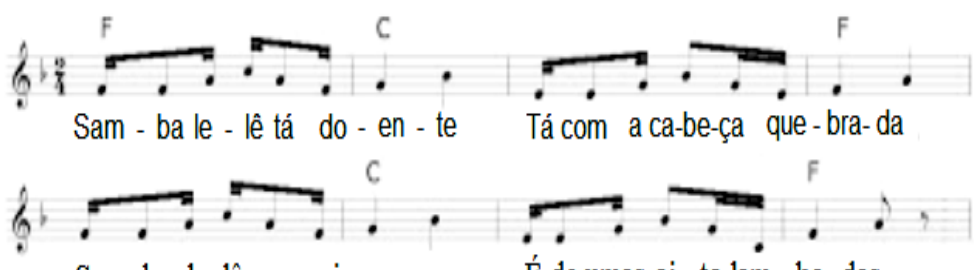

Sam -ba -le- lê pre-ci - sa - va É de umas oi - to lam - ba -das.

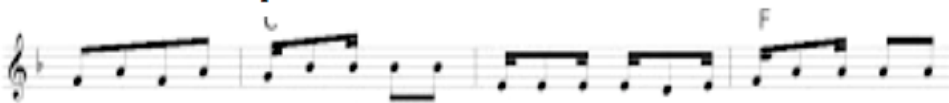

Pi - sa, pi- sa, pi - sa mu - la - ta Pi - sa na ba - rra da sai -a mu - la - ta!

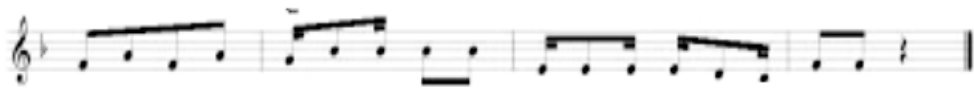

Pi-sa, pi-sa, pi-samu-la-ta P1-sa na ba-ma da sai-a.

Figura 3: Letra e partitura da música "Sambalelê"

\section{Atividade 4: 0 jogo}

Público-Alvo - Turmas a partir do 5o ano do Ensino Fundamental (não há limite máximo de idade).

Objetivo - Vivenciar o pulso, 1ำ tempo do compasso, com a música de divisão binária (compasso binário).

\section{Desenvolvimento}

1. Dividir a turma em duplas. Cada dupla recebe uma pedrinha ou caixa de fósforos vazia.

2. Organizados em duplas, um de frente para o outro, deverão cantar a música Escravos de Jó, (Fig. 4) trocando entre si a pedra de acordo com o ritmo que a música propõe.

\section{Os escravos de Jó}

\section{Escravos de Jó (versão Zambelê)}

Escravos de Jó, jogavam caxangá Tira, bota, deixa o Zambelê ficar... Guerreiros com guerreiros fazem zigue zigue zá

Guerreiros com guerreiros fazem zigue zigue zá.

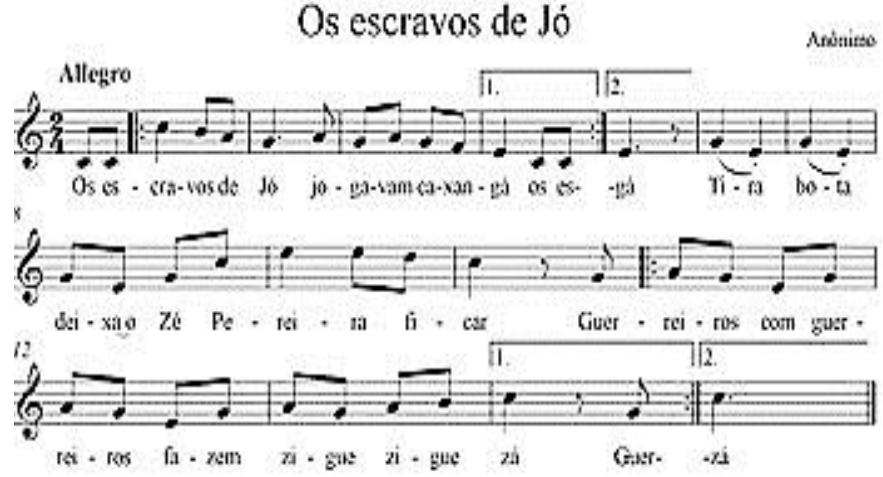

Figura 4: Letra e partitura da música "Escravos de Jó"

Observação - O toque da pedra sobre a mesa caracteriza o pulso da música. 


\section{Atividade 5: Tabuada de Multiplicação}

Público-Alvo - Turmas a partir do 3a ano do Ensino Fundamental

Objetivo - Praticar a tabuada de multiplicação do número "cinco".

\section{Desenvolvimento}

Cantar a tabuada de 5 (cinco) usando a melodia da música.

\section{Escravos de Jó (Modificada)}

De 5 em 5 vamos saltear Pense, cante, deixe rolar É 5 , é 10 , é 15 , é 20 , depois 25 ! (bis)

Depois do 25 o que será que tem? (bis) Pense, cante, tente dizer É 30, é 35, como é fácil de aprender! (bis)

Depois do 35 o que será que tem? (bis) Pense, cante, tente cantar 40,45 , e 50 pra acabar! (bis)

Figura 5: Letra da música "Escravos de Jó"

\section{CONCLUSÕES}

Espera-se que as sugestões feitas neste trabalho possam contribuir para que professores do ensino fundamental se sintam motivados a dar passos na direção de proporcionar, através da Música, meios não só de revisar e reforçar tópicos de diversos conteúdos, mas também de proporcionar aos educandos uma consciência musical.

Que a Música deixe de ser apenas um elemento recreador, para tornar-se uma forte aliada de aulas motivadoras, participativas e desafiadoras.

A Música torna as crianças mais sensíveis, pacientes, com maior concentração e percepção de detalhes - favorecendo-Ihes, assim, o desenvolvimento da capacidade de abstração - e, consequentemente, facilita a aprendizagem.

\section{REFERÊNCIAS}

Brasil. Ministério da Educação. Resolução CNE/CP n. 1, de 15 de maio de 2006. Institui Diretrizes Curriculares Nacionais para o Curso de Graduação em Pedagogia, licenciatura, 2006. Disponível em: <http://portal.mec.gov. br/cne/arquivos/pdf/rcp01_06.pdf>. Acesso em: 12 mar. 2014.

Ferreira, Denise Luzia de Amorim. et al. A influência da linguagem musical na educação infantil. Disponível em $<$ http://www.histedbr.fae.unicamp.br/acer_histedbr/jornada/jornada7/_GT4\%20PDF/A\%20INFLU\%CANCIA\%20 DA\%20LINGUAGEM\%20MUSICAL\%20NA\%20 EDUCA\%C7\%C30\%20INFANTI1.pdf>. Acesso em: 01 abr. 2014.

Figueiredo S. L. F., Alberti G.C. A Música nas Séries iniciais do Ensino Fundamental: Orientações para seu Ensino em Vitória (ES) e no Distrito Federal. Anais do XIX Seminário de Iniciação Científica. 2007. Disponível em <http://www.ceart.udesc.br/revista_dapesquisa/volume4/ numero1/musica/amusicanasseries.pdf > . Acesso em: 22 mar. 2014.

MOTTA, Carlos Eduardo Mathias. Projeto DRUMMATH: uma perspectiva walloniana no ensino da Matemática para o deficiente visual através de sons e ritmos. 1999. Disponível em: <http://www.uff.br/dalicenca/images/stories/caderno/volume5/Projeto_DRUMMATH.pdf>. Acesso em: 22 nov. 2014

Morais, J. JOTA de. O que é música? Coleção Primeiros Passos. Editora Brasiliense, Rio de Janeiro. 1983.

Simonato, Adriano Luis. Relação Matemática e Música. 2006. Disponível em: <http://www.unifafibe.com. br/revistasonline/arquivos/revistafafibeonline/sumario/9/18052011154859.pdf> Acesso em: 22 nov. 2013. 